\title{
A STUDY OF THE LONGEVITY OF MALES AT DIFFEREN'T PERIODS IN THE HISTORY OF GREAT BRITAIN AND .IRELAND FROM THE SIXTEENTH TO THE BEGINNING OF THE NINETEENTH CENTURY, BASED ON DATA FROM THE "DICTIONARY OF NATIONAL BIO- GRAPHY" AND “BURKE'S PEERAGE AND BARONETAGE."
}

\author{
By MATTHEW YOUNG, M.D., and W. T. RUSSELL.
}

(With 2 Graphs.)

INTRODUCTION.

THE life tables that have been constructed from the recorded mortality in England and Wales as a whole at more or less regular intervals since registration of death was introduced in 1837, and those that have been prepared for special districts and cities at various times since that date, afford accurate information regarding the average length of life at different periods during the greater part of last century. There is still comparatively little known, however, about the mean duration of life, and the conditions of health on which it so largely depends, amongst those who lived in the British Isles in pre-registration times and the present paper contains the results of an attempt to supplement existing knowledge on this subject. The data on which the paper is based have been derived from two sources, namely, the Index and Epitome of the Dictionary of National Biography and Burke's Peerage and Baronetage. In the first of these are records of the dates of birth and death with brief summaries of the life histories of persons who were selected as being eminent in various spheres of life in the British Isles and the Colonies from the earliest historical period; in the second are given the genealogical histories of members of the different titled families.

The previous work on the duration of life in the centuries preceding the introduction of registration is not extensive but attempts have been made by other investigators to obtain from various sources some information on the subject. The average lifetime in the peerage or peerage and baronetage has been the subject of study by several writers notable among whom are Edmonds, Guy and Day. Edmonds' (1839) enquiry related to peers only and was based on a small number of observations. Guy's (1845) investigation related to the peerage and baronetage and comprised the data for the period between 1300 and 1830. For the calculation of his table of expectations at 
the different ages, he included all males who died over 21 years of age up to 1830 , except those who were killed in battle or by accident. Day's (1861) investigation related to the last half of the eighteenth and the first half of the nineteenth century and was restricted to peers, their sons and daughters and the sons and daughters of the eldest sons of peers, as he believed that the inclusion of the collateral branches of the peerage would lead to the loss of the distinctive features of the highest social class. The results of Guy's investigation have been criticised by Day because he has calculated his expectations from deaths only and has taken no account of those in the universe considered who were surviving at the several ages at the date of the conclusion of the investigation. The criticism appears to be justified and the expectations given in Guy's table cannot be considered reliable; the expectations of life based on deaths alone can only give accurate results if the population is stationary. Guy's enquiries extended beyond the peerage and baronetage. He published in the Journal of the Royal Statistical Society, between the years 1846 and 1859, a series of papers in which he discussed the length of life observed among those following the several professions who had achieved eminence in some form or other in the history of this country.

Since Guy wrote, the data available for an adequate investigation of the length of life of those who have attained eminence in Britain have become much more numerous. The Dictionary of National Biography, on which the present discussion is partly based, alone contains an amount of fairly homogeneous material nearly ten times as large as that used by Guy. Further, writing, as he did, between 1840 and 1850 and taking no account of survivors at the different ages, he could only with safety consider the length of life of persons born before 1750 , whereas, at the present time, data for births as late as 1810 from the Dictionary which describes completed lives only, and as late as 1820 from Burke's Peerage, can be included with the great advantage that this extension brings the scope of the investigation to within twenty years of the date of the first life table prepared from the mortality data obtained after the introduction of registration. The tables of expectations of life deduced from the data for eminent men and members of the peerage and baronetage born in certain epochs up to the beginning of the nineteenth century, can be compared with this life table and with more recent life tables prepared from the data both for England and Wales as a whole and for special districts.

\section{NATURE OF DATA AND PREPARATION FOR ANALYSIS.}

In compiling the data for analysis, the particulars that were transferred to cards from the two publications were not identical. In the Dictionary of National Biography, the dates of birth and death, the mode of death, i.e. whether from violence or natural causes, and the nature of the social class or profession to which each member of the male sex belonged, were extracted. Twelve classes or professions were distinguished, namely, (1) Royalty, 
(2) Peerage, (3) Politics, (4) Army, (5) Navy, (6) Divinity, (7) Law, (8) Science, (9) Literature, (10) Arts, (11) Commerce and (12) Miscellaneous. This classification can only be regarded as approximately correct as at times it was difficult to make the proper allocations, but, broadly considered, those included in the different groups are in all probability fairly representative of the classes, social or professional, indicated. Numerous entries were incomplete inasmuch as either the date of birth or death was not recorded, but, excluding these, the duration of life was determinable in fully 20,000 instances. It would be more easy to assail than to defend the contention, if this were made, that the entries in the Dictionary should be accepted as an entirely uniform body of statistics. It is well known that attainment of eminence such as might receive recognition by insertion in this national document may be achieved at a much earlier age in some professions than in others and it is also recognised that standards of eminence may have been modified not inconsiderably with the passage of centuries. The original dictionary and the first supplement, which are all that are included in the investigation, form a work that was carried through on quite definite principles by the two editors, Sir Leslie Stephen and Sir Sidney Lee, under the supervision of the initiator and proprietor and to this extent may be regarded as homogeneous. In Burke's Peerage and Baronetage, the dates of birth and death, and in addition the conjugal condition, the year of marriage, the number of children per marriage and the duration of marriage were tabulated for all entries of the male sex. As in the Dictionary, many entries were incomplete but the dates of birth and death were given in approximately 12,000 instances. The age of each person at death was the only item of his record utilised in the present analysis. As the dates of birth of women are not given in Burke's Peerage, it was impossible to obtain any similar data for the female sex.

It may be as well before proceeding further to explain that the age at death used in all the calculations is the integral number obtained by subtracting the year of birth from the year of death. This number may in extreme cases be nearly a year in excess or in defect of the true age. For example, a person born on December 31st, 1800, and dying on January 1st, 1830, would appear as 30 years of age, though really only 29 years old, and a person born on January 1st, 1800, and dying on December 31st, 1830, would also appear as 30 years old, though actually 31 years of age all but one day. As errors in excess and defect are equally probable they tend to balance out in taking an average and the method adopted gives the mean age at death.

The present investigation has been carried out by means of tables which show, in the several comparable groups, the expectation of life at definite age intervals for different periods of years. Separate tables showing the expectation of life at age 30 and at successive age intervals of 5 years have been constructed for the men of eminence who were born in each of the 30 years' periods from 1551 to 1790 , and in the 20 years' period 1791 to 1810 ; and in the case of the peerage for those born in the 30 years' periods beginning at 
1551 and ending at 1820 . The data for births prior to 1551 were not sufficiently numerous to merit separate treatment. By the appropriate summation of the data for the period 1501-1550 and the 30 years' periods from 1551 onwards, the totals for eminent men and peers born in each of the three longer epochs, 1501-1610, 1611-1700 and 1701-90, were obtained. Though these epochs do not correspond exactly to the sixteenth, seventeenth, and eighteenth centuries, they do so for all practical purposes, and, from the data thus obtained, separate tables of expectation, which may be considered as representing the three centuries, were calculated for the two groups. Tables of expectations of life were also calculated, but are not published, for eminent men born in the successive decennial periods comprising the epoch 1761-1810, in which the entries in the Dictionary for each year were much more numerous than for the previous years. In each of these decades, the number of observations usually exceeded 1000. The figures thus deduced have been supplemented by some tables of expectations relating to the data for the special classes or professions extracted from the Dictionary of National Biography. The calculations have, however, been restricted to a few cases. As with each sub-division the total number in each group becomes smaller, and as the sampling error affecting a result increases as the number in the group diminishes, it was considered inadvisable to calculate the expectations at the different ages in those classes with relatively small numbers of observations. Five classes have been chosen for special investigation. These are Divinity, Literature, Science, Arts, and Miscellaneous. The tables of expectations of life have been calculated for each 30 years' period from 1551 to 1810 for the first two and the last of these classes and for similar periods from 1701 to 1810 for those following the professions of Science and Arts. From these tables, the figures for the epochs 1551-80, 1611-40, 1671-1700, 1731-60 and 1791-1810 have been selected for comparison.

\section{Analysis and Discussion of Data.}

Having indicated briefly the various tables of expectation of life that have been constructed for eminent men and members of the peerage, we now proceed to their analysis and discussion. The expectations of life in the different 30 years' periods are given in Table $I$ and are shown graphically in Graph I. From this table and graph, it will be seen that the expectations of life at the different ages for those born in the 30 years' period 1551-80, who were members of titled families or who attained eminence later, are practically identical, the values at age 30 being 33.46 and 33.37 years and at age 50, 18.29 and 18.23 years respectively, but undue emphasis need not be placed on this equality as the numbers in the peerage group are perhaps too small to furnish a reliable index. The trend of Graph I, which traces the expectations at age 30 for the two sets of data, strongly suggests that the values of the expectations shown for the peerage during the epoch 1551-80 are too high, 


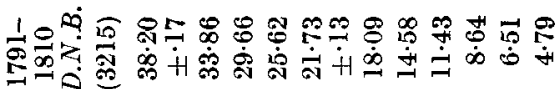

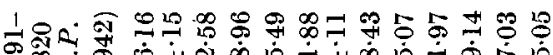

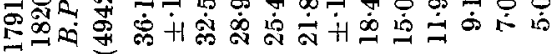

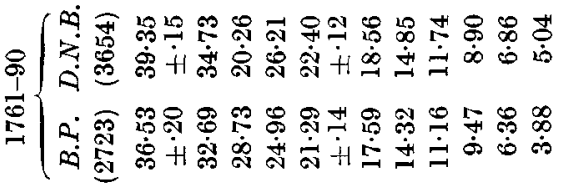
\&

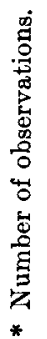

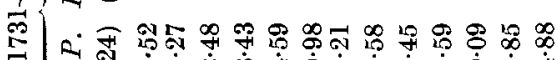

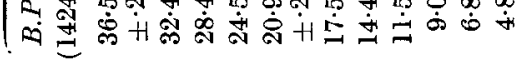

(

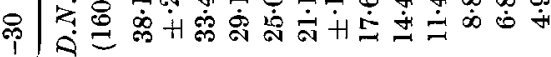
은 R

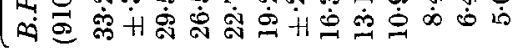

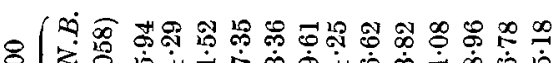

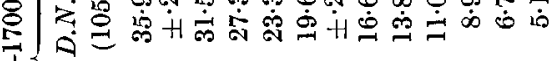

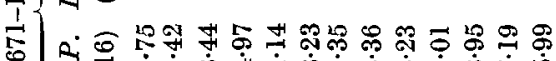

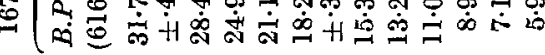

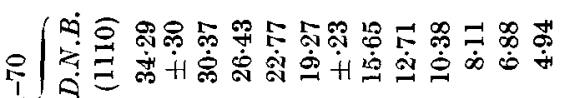

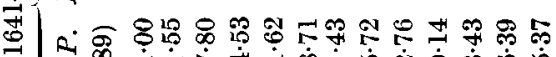

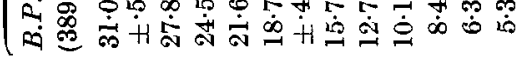

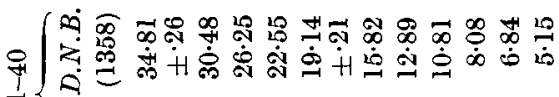

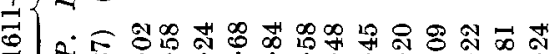

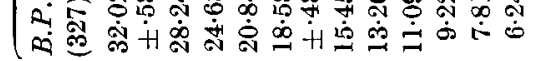

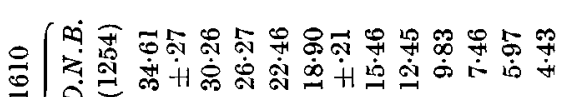
$1\{$ व

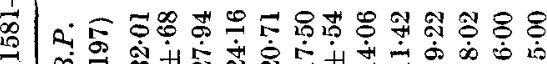
Q (

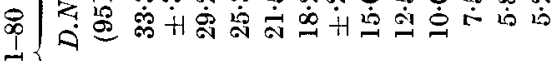

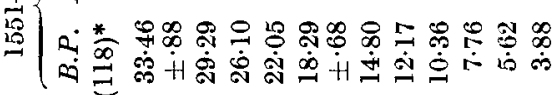

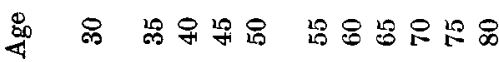


as in all the other 30 years' periods the curves run nearly parallel, with the figures for the peerage at a sensibly lower level than those for eminent men. The graph also shows that amongst eminent men the expectation of life reaches a maximum of 39.35 years for those born in the period 1761-90. For those born in the following 20 years, the expectation declines about one year. This fall appears to be statistically significant. The expectation tables for the

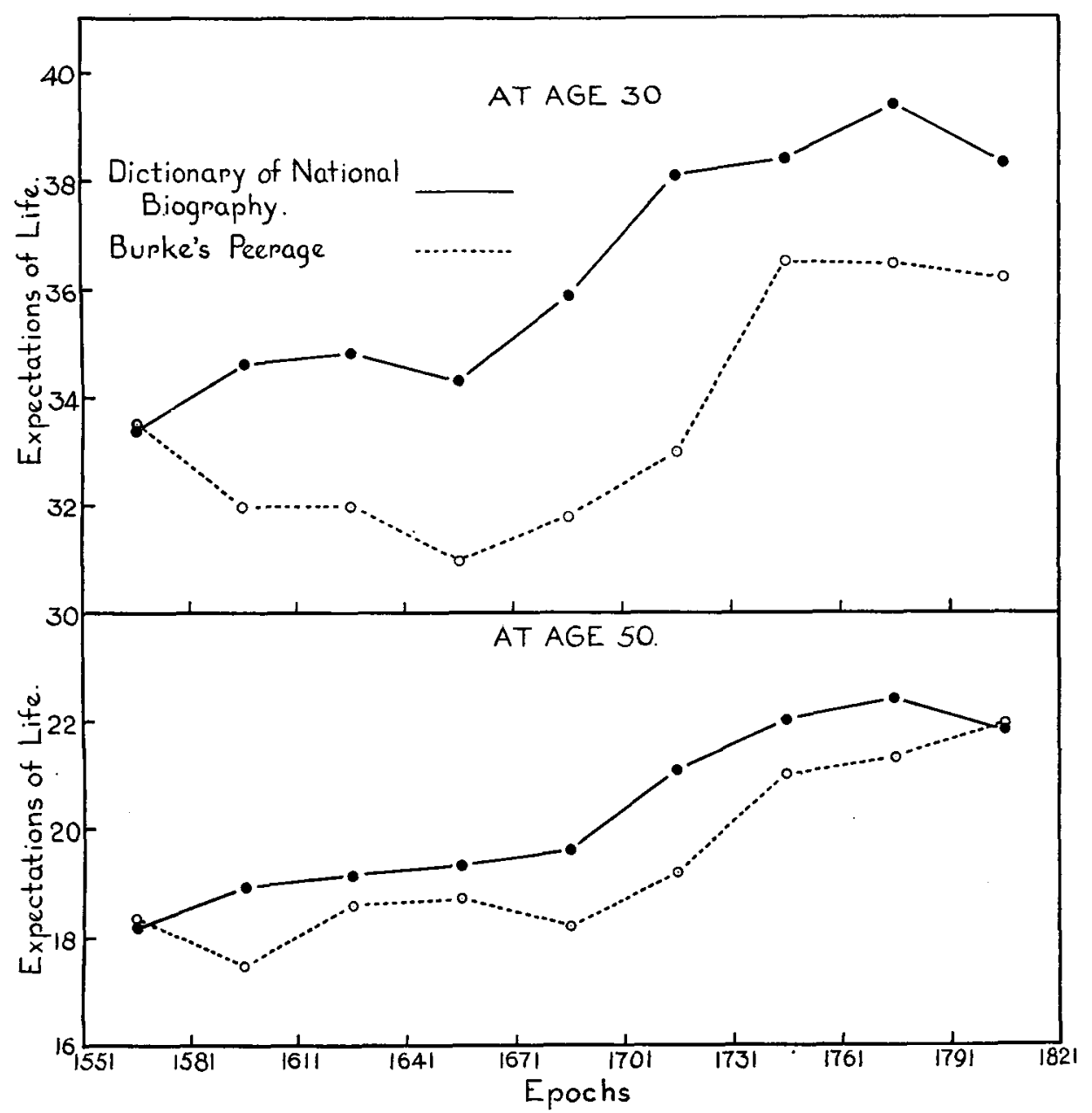

Graph I. Showing the expectations of life at ages 30 and 50 in successive 30 years' epochs from 1551 to 1820 .

decennial periods from 1761 to 1810 , which are not published, indicate that the expectations at the ages 30 and 50 years actually attain their maximal values for those born in the decade 1771-80. The increase in expectation of life among men of eminence that takes place from 1551 to 1761 is not regular. For those born in the two periods, 1581-1610 and 1611-40, the expectation of life at 30 remains practically unchanged at $34 \cdot 61$ years. For those born 
in 1641-70, there is a slight decline of about half a year as compared with the previous period, but this fall is not significant in view of the magnitude of .ts probable error. This is followed by a more pronounced increase of practically two years in each of the next two epochs. Thereafter, the rate of increase is less marked till the maximum is reached. The expectation of life at age 50 for eminent men shows a gradual increase for those born in the successive epochs from 18.23 years in $1551-80$, to 22.40 years in $1761-90$, but declines by about 0.5 of a year in the succeeding 20 years' period. The expectations at 50 may perhaps be chosen as representing the facts rather more accurately than the expectations at 30 , inasmuch as a majority of those who attain eminence have usually done the work by which their ultimate position is judged before the age of 50 years is reached.

With regard to the peerage, the expectation at age 30 years for those born in 1551-80 is 33.46 , but as has been already mentioned, this figure has a relatively large probable error and cannot be considered to be very reliable. For those born in the succeeding 30 years' period the expectation is lower by 1.5 years and remains at this level in the subsequent 30 years' period. In these two periods, the expectation at 30 is from 2.5 to 3 years less than that at the corresponding age for eminent men. For those born in the peerage from 1641 to 1670 , the expectation at 30 has fallen to 31.00 . Considering the size of the probable error no significance can be attached, however, to this decline of one year from that shown in the preceding epoch. In this period the expectation is fully 3 years lower than the expectation at the corresponding age in men of eminence. After 1641-70, the expectation generally rises in successive periods and reaches 36.52 years for those born in 1731-60; it remains approximately at the same level for those born in the two following epochs 1761-90 and 1791-1820.

The mean after-lifetime or expectation at age 50 for those born in the peerage in the epoch $1551-80$ is 18.29 years. It shows only slight variations within the range of the probable errors for those born in the successive 30 years' periods from 1551 to 1700 ; in the last of these it is 18.23 years. From 1700 onwards, the expectation of life at age 50 gradually increases till it attains a value of 21.88 years in the period 1791-1820. The expectations of life at age 50 for eminent men exceed those for members of the peerage in all the epochs except 1551-80 and 1791-1820 in which they are practically identical. The differences in expectation in the two classes in favour of the eminent men vary somewhat irregularly from $0 \cdot 6$ of a year in the 30 years' period 1611-40 to nearly two years in the period 1701-30, but considering the magnitudes of their probable errors they can only be regarded as significant in the epochs from the end of the seventeenth century onwards.

It has been suggested that the increase in expectation of life shown in the peerage data for those born in the periods 1701-30 and 1731-60 (Table I) may be due to the fact that the roll of peers was considerably augmented by new creations during the reign of George III. On the accession of this king 
in 1760 there were only 174 British peers but between this date and 1783 about 72 peers were created or promoted and during the administration of Pitt from 1783 to 1801 the number of new creations or promotions in the peerage was upwards of 140 (Lecky 1887). To determine the effect on the mean after-lifetime of the addition to the peerage of this relatively large number of men who were with few exceptions over 50 years of age, particulars of the peerages created between the years 1750 and 1810 were obtained and the dates of birth and death of the first holders of the titles ascertained by reference to Burke's Peerage. Of these peers, 46 were born in the period 1701-30 and 60 in the period 1731-60. On deducting the years of life lived by these newly created peers from the data for the life tables for the corresponding periods and recalculating the expectations of life, the expectation at age 50 for those born in 1701-30 was only reduced by 0.3 of a year and that in the succeeding period remained unchanged.

Many baronets were also created in the period $1760-1810$. Of these 30 were born in the period $1701-30$ and 64 in the subsequent 30 years' period. The exclusion of these from the life tables for the corresponding periods produced no change in the expectation of life at age 50. It would thus appear that the increased expectation of life at this age shown in the life tables published for those born in the early part of the eighteenth century and belonging to the highest social class is not determined by the considerable augmentation of the peerage and baronetage that took place in the latter half of the century.

It may be as well to state at the present stage that, as the expectations of life at different ages for the data in Burke's Peerage were calculated from the deaths as a whole without excluding those who died from what may be described as violent causes, the expectations for eminent men based on all the deaths are also tabulated so that they may be more truly comparable with those in the other group. The expectations for eminent men were, however, recalculated after excluding those who died from violence. This usually resulted in a reduction of the expectation at age 30 only to the extent of about half a year, and in practically no change at age 50, so that the expectations given would not be very materially altered by excluding these cases.

The principal features of Table I seem to be the gradual though not entirely regular increase in expectation of life in successive epochs in both eminent men and in members of the peerage families till near the end of the eighteenth century and the divergence between the expectations of life shown at the earlier ages in the two sets of data. These features are exhibited more concisely in Table II which gives the expectations of life at the different ages for the men of eminence and peers who were born in the sixteenth, seventeenth and eighteenth centuries, respectively. Both eminent men and members of the peerage born in the eighteenth century show a definite increase in expectation of life at the different ages over those shown for the corresponding classes in the previous century. The expectations of life in the seventeenth century, however, do not differ greatly and probably not sensibly from those shown 
in the sixteenth. The expectations of life calculated from the data in Burke's Peerage for all those born in the eighteenth century are very similar to the expectations calculated by Day for those in the direct line of the peerage who lived in the period 1755-1855. From this it may be inferred that those in the direct line of the peerage do not experience on the average a longer lifetime than the aggregate of those in its collateral branches.

The question now arises: do the expectations of life in the tables, which have been calculated for eminent men and members of the peerage born in different epochs in pre-registration times, exhibit changes in conformity with those found in recent life tables constructed from more numerous data on

Table II. Showing a comparison of the expectations of life at the different ages in the two groups of data from Burke's Peerage and the Dictionary of National Biography, for those born in the sixteenth, seventeenth and eighteenth centuries, as well as a comparison of the expectations shown by those in the direct line of the peerage who were living in the period 1755-1855 as calculated by Day, with those obtained from all the entries in the peerage who were born in the eighteenth century and were thus living in an approximately similar period.

\begin{tabular}{|c|c|c|c|c|c|c|c|}
\hline \multirow[b]{2}{*}{ Age } & \multicolumn{2}{|c|}{$1501-1610$} & \multicolumn{2}{|c|}{$1611-1700$} & \multicolumn{2}{|c|}{$1701-90$} & 1755-1855 \\
\hline & $\begin{array}{c}\text { Burke's } \\
\text { Peerage } \\
\text { (394)* }\end{array}$ & $\begin{array}{c}\text { Dictionary } \\
\text { of National } \\
\text { Biography } \\
(2717)\end{array}$ & $\begin{array}{c}\text { Burke's } \\
\text { Peerage } \\
\text { (1332) }\end{array}$ & $\begin{array}{c}\text { Dictionary } \\
\text { of National } \\
\text { Biography } \\
(3526)\end{array}$ & $\begin{array}{c}\text { Burke's } \\
\text { Peerage } \\
\text { (5057) }\end{array}$ & $\begin{array}{c}\text { Dictionary } \\
\text { of National } \\
\text { Biography } \\
(7726)\end{array}$ & $\begin{array}{l}\text { Day's figures } \\
\text { for males in } \\
\text { direct line } \\
\text { of peerage }\end{array}$ \\
\hline 30 & $33 \cdot 11 \pm-50$ & $34 \cdot 02 \pm \cdot 18$ & $31 \cdot 60 \pm \cdot 29$ & $34.98 \pm \cdot 16$ & $35 \cdot 93 \pm \cdot 14$ & $38 \cdot 78 \pm \cdot 11$ & $35.01 \dagger$ \\
\hline 35 & $29 \cdot 10^{-}$ & $29 \cdot 74$ & $28 \cdot 20$ & $30 \cdot 76$ & $32 \cdot 08$ & $34 \cdot 18$ & $31 \cdot 47$ \\
\hline 40 & $25 \cdot 58$ & $25 \cdot 73$ & $24 \cdot 77$ & $26 \cdot 64$ & $28 \cdot 26$ & $29 \cdot 84$ & $27 \cdot 83$ \\
\hline 45 & $22 \cdot 10$ & $21 \cdot 95$ & $21 \cdot 45$ & $22 \cdot 87$ & $24 \cdot 46$ & $25 \cdot 83$ & $24 \cdot 30$ \\
\hline 50 & $18 \cdot 60 \pm \cdot 39$ & $18 \cdot 52 \pm \cdot 15$ & $18 \cdot 45$ 上. 24 & $19 \cdot 32 \pm \cdot 13$ & $20 \cdot 84 \pm \cdot 11$ & $22 \cdot 02 \pm \cdot 09$ & $20 \cdot 90$ \\
\hline 55 & $15 \cdot 00^{-10}$ & $15 \cdot 20^{-}$ & $15 \cdot 48$ & $16 \cdot 01$ & $17 \cdot 38$ & $18 \cdot 28$ & $17 \cdot 50$ \\
\hline 60 & $12 \cdot 29$ & $12 \cdot 41$ & $13 \cdot 08$ & $13 \cdot 12$ & $14 \cdot 16$ & $14 \cdot 73$ & $14 \cdot 06$ \\
\hline 65 & $10 \cdot 32$ & $9 \cdot 99$ & $10 \cdot 82$ & $9 \cdot 77$ & $11 \cdot 25$ & $11 \cdot 72$ & $10-91$ \\
\hline 70 & $8 \cdot 18$ & $7 \cdot 69$ & $8 \cdot 86$ & $8 \cdot 36$ & $8 \cdot 64$ & 8.94 & $8 \cdot 27$ \\
\hline 75 & $6 \cdot 35$ & $6 \cdot 14$ & $7 \cdot 11$ & $6 \cdot 83$ & 6.52 & $6 \cdot 81$ & $5 \cdot 98$ \\
\hline 80 & $5 \cdot 14$ & 4.88 & $6 \cdot 33$ & $5 \cdot 10$ & $4 \cdot 81$ & $4 \cdot 99$ & $4 \cdot 08$ \\
\hline & * No. of & observations & & & $\dagger 0.5$ of & ear deduc & \\
\hline
\end{tabular}

which, therefore, more reliance can be placed? What is the relation of the expectations deduced to those at corresponding ages in life tables from other data? This can be shown best by comparing them with life tables which have been prepared from data obtained since the introduction of registration. The first life table which refers to England as a whole was constructed by Farr from the census returns for the year 1841 and the mortality data ascertained by registration for the corresponding year. Two more important life tables, as they embraced a longer experience, were soon afterwards prepared by the same author, the English life table No. 2 based on the census enumerations of 1831 and 1841 and the recorded deaths of the 7 years' period 1838-44, and the English life table No. 3 based on the census returns of 1841 and 1851 and the mortality data from 1838 to 1854 . The results in these life tables are in 
very close agreement and the last may be taken as representative of the others. This table was followed by numerous others of which that for the decade 1891-1900 may be taken for comparison. These tables represent the average of the whole community. From the mortality data for the healthy districts of the country, i.e. those districts with death-rates under a certain value, life tables have also been constructed and the two that correspond most closely in time with those already mentioned for the whole country, are the healthy districts life table of Farr based on data from districts with a mean annual death-rate under 17 per thousand in the years 1849-53, and the healthy districts life table of Tatham for districts with a mortality under 14 per thousand in the decade 1891-1900. The difference between the expectations for males at age 30 in the two life tables for England as a whole, does not amount to more than 0.4 of a year and the difference between the similar values in the two healthy districts life tables is at most 0.9 of a year. The difference between the values taken from life tables for England as a whole and those from the healthy districts life table at the age of 30 is, however, over 4 years and even at the age of 50 about 3 years. These two sets of figures from the life tables for the country as a whole and the healthy districts represent different conditions of health which may be taken for comparison with the values of the expectations which have been deduced for eminent men and members of the peerage born in different epochs before the introduction of registration.

In Table III, a comparison is made between the expectations of life, at the different ages, of eminent men born in the period 1551-80, and of members of the peerage born in 1581-1610 (the statistics of the peerage in 1551-80 not being regarded as so reliable as those for the succeeding period), and the expectations at the corresponding ages for the general population of England and Wales during the decades 1891-1900 and 1881-90, respectively.

Table III. Showing the expectations of life at the different ages in data from the Dictionary of National Biography and Burke's Peerage, for those born in the 30 years' periods 1551-80 and 1761-90, in comparison with the expectations at corresponding ages in recent life tables.

\begin{tabular}{|c|c|c|c|c|c|c|c|c|}
\hline \multirow[b]{2}{*}{ Age } & \multirow{2}{*}{$\begin{array}{c}\text { 1581-1610 } \\
\text { Burke's } \\
\text { Peerage }\end{array}$} & \multirow{2}{*}{$\begin{array}{l}\text { 1881-90 } \\
\text { England } \\
\text { and } \\
\text { Wales }\end{array}$} & \multirow{2}{*}{$\begin{array}{c}155 \mathrm{l}-80 \\
\text { Dictionary } \\
\text { of National } \\
\text { Biography }\end{array}$} & \multirow{2}{*}{$\begin{array}{l}\text { 1891-1900 } \\
\text { England } \\
\text { and } \\
\text { Wales }\end{array}$} & \multicolumn{2}{|c|}{$1761-90$} & \multirow{2}{*}{$\begin{array}{l}1891-1900 \\
\text { Healthy } \\
\text { Districts } \\
\text { of England } \\
\text { and Wales }\end{array}$} & \multirow{2}{*}{$\begin{array}{c}\text { 1911-12 } \\
\text { Rural } \\
\text { Districts } \\
\text { of England } \\
\text { and Wales }\end{array}$} \\
\hline & & & & & $\begin{array}{l}\text { Burke's } \\
\text { Peerage }\end{array}$ & $\begin{array}{l}\text { Dictionary } \\
\text { of National } \\
\text { Biography }\end{array}$ & & \\
\hline 30 & $32 \cdot 01$ & $32 \cdot 02$ & $33 \cdot 37$ & 32.57 & $36 \cdot 53$ & $39 \cdot 35$ & $36 \cdot 82$ & $38 \cdot 14$ \\
\hline 35 & 27.94 & $28 \cdot 41$ & $29 \cdot 24$ & $28 \cdot 74$ & $32 \cdot 69$ & $34 \cdot 73$ & 32.82 & 33.97 \\
\hline 40 & $24 \cdot 16$ & $24 \cdot 92$ & $25 \cdot 32$ & $25 \cdot 14$ & $28 \cdot 73$ & $30 \cdot 26$ & $28 \cdot 87$ & $29 \cdot 82$ \\
\hline 45 & $20 \cdot 71$ & $21 \cdot 56$ & $21 \cdot 53$ & $21 \cdot 70$ & $24 \cdot 96$ & $26 \cdot 21$ & 24.99 & $25 \cdot 81$ \\
\hline 50 & 17.50 & $18 \cdot 32$ & $18 \cdot 23$ & $18 \cdot 40$ & $21 \cdot 29$ & $22 \cdot 40$ & 21.24 & $21 \cdot 89$ \\
\hline 55 & $14 \cdot 06$ & $15 \cdot 24$ & 15.08 & $15 \cdot 29$ & $17 \cdot 59$ & $18 \cdot 56$ & $17 \cdot 62$ & $18 \cdot 13$ \\
\hline 60 & $11 \cdot 42$ & $12 \cdot 38$ & $12 \cdot 59$ & $12 \cdot 43$ & $14 \cdot 32$ & $14 \cdot 85$ & $14 \cdot 22$ & $14 \cdot 63$ \\
\hline 65 & $9 \cdot 22$ & $9 \cdot 81$ & $10 \cdot 08$ & $9 \cdot 84$ & $11 \cdot 16$ & $11 \cdot 74$ & $11 \cdot 11$ & $11 \cdot 45$ \\
\hline 70 & 8.02 & $7 \cdot 54$ & $7 \cdot 53$ & 7.95 & $9 \cdot 47$ & 8.90 & $8 \cdot 34$ & $8 \cdot 61$ \\
\hline 75 & $6 \cdot 00$ & $5 \cdot 60$ & $5 \cdot 86$ & $5 \cdot 65$ & $6 \cdot 36$ & $6 \cdot 86$ & $6 \cdot 06$ & $6 \cdot 31$ \\
\hline 80 & $5 \cdot 00$ & $4 \cdot 02$ & $5 \cdot 25$ & $4 \cdot 12$ & $3 \cdot 88$ & 5.04 & $4 \cdot 28$ & 4.51 \\
\hline
\end{tabular}


To make the expectations of life at the different ages in the two English life tables more truly comparable with those calculated for eminent men and members of the peerage, 0.5 of a year must be deducted from the former owing to the method of determining the ages in the data at present under investigation (see p. 258). It will be seen that the series of expectations at the corresponding ages in the two periods are in fairly close agreement. The vitality of the eminent men born in the second half of the sixteenth century and living during the Elizabethan epoch is thus represented fairly well by that shown by the average male in England and Wales as a whole in 18911900 or the end of last century, while the vitality of members of the peerage families born towards the end of the sixteenth century is rather less, and is more nearly equivalent to that shown in England and Wales in the decade 1881-90. On comparing the tables of expectations of life of those born in the period 1761-90 and thus living during the latter half of the eighteenth and the first half of the nineteenth centuries who belonged to the peerage or who later attained eminence, with the healthy districts life table for 18911900 , it will be seen that the vitality of male members of the peerage families resembles very closely that for males in the healthy districts at the end of the nineteenth century while the vitality of eminent men born in the corresponding period is definitely in excess of that in males from the healthy districts; indeed, the mean after-lifetime of these eminent men exceeds by fully a year at age 50 that of men living in the rural districts of England and Wales at the beginning of the twentieth century, as given in the rural districts life table for England and Wales for 1911-12. The eminent men and those born into the peerage at the earlier and later epochs thus represent fairly closely two types of vitality which have been found in England and Wales in the last, and the beginning of the present, century.

It may be of interest to mention that the expectations of life at ages 30 and 50 years in the members of the peerage families who were living in the latter half of the eighteenth and the first half of the nineteenth century, expectations which, as already stated, are almost identical with the values shown in the Healthy Districts life table for England and Wales in 1891-1900, exceed by 1.5 and 1 year, respectively, those at the corresponding ages in the well-known life table, $\mathrm{OM}^{1}$, based on selected lives.

We now proceed to consider and to compare the expectations of life that have been calculated for special groups or classes of eminent men born in certain epochs, and those of eminent men in the aggregate belonging to the same epochs. The results in the periods selected for comparison are given in Table IV and the trends of the expectations at ages 30 and 50 years in each of the several classes are shown in Graph II. The same general characteristics are exhibited in all. They all show that the expectation of life at 30 years of age has definitely increased in the period under review. The differences in the

1 Combined Experience of Assured Lives (1863-93). Institute of Actuaries and Faculty of Actuaries Joint Mortality Investigation, 1900. 
Matthew Young and W. T. Russeli
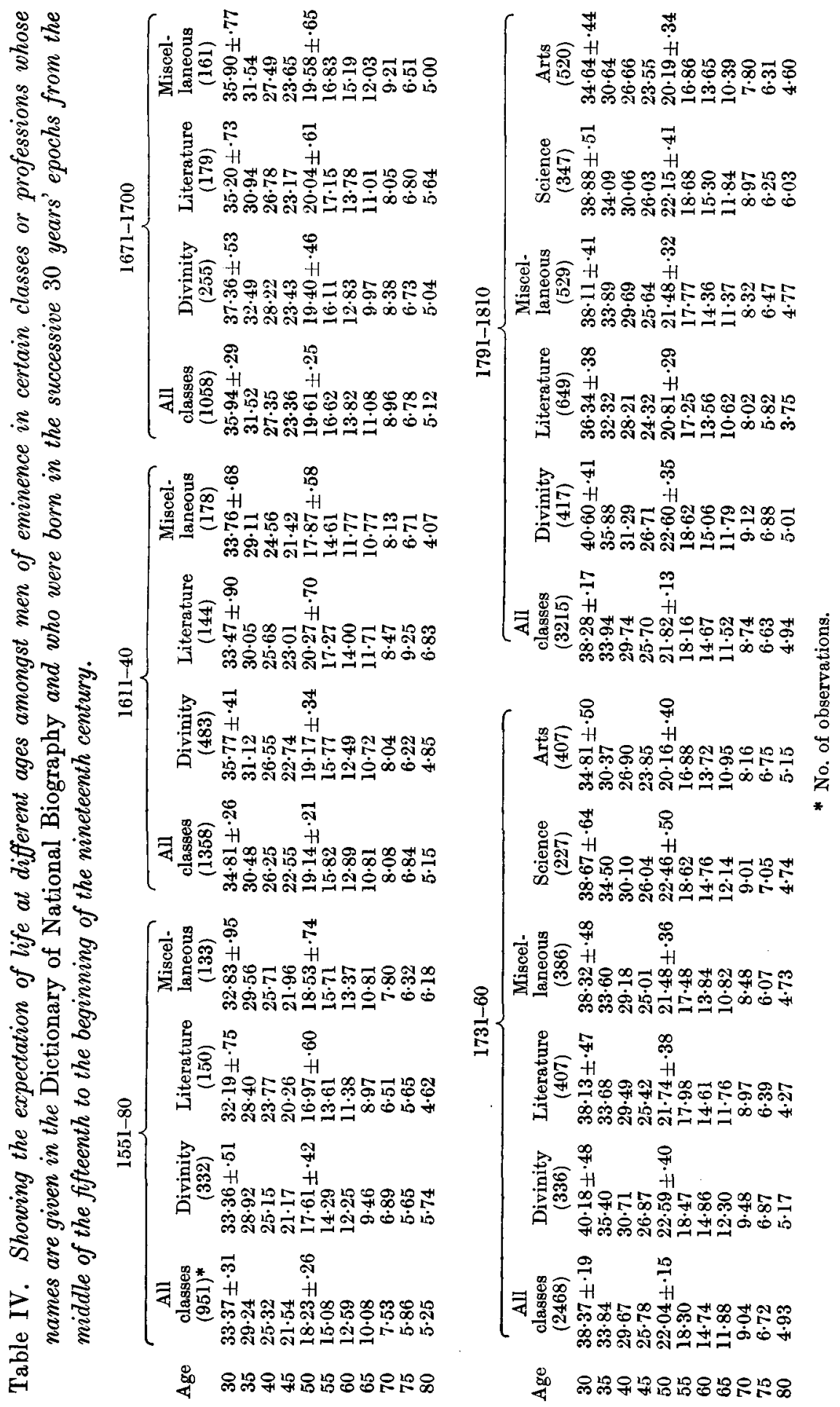
rate of change in the different groups can scarcely be regarded as significant. The clergy appear to have on the whole a somewhat higher expectation of life at age 30 than that found amongst those who have chosen literature as a profession, while those included in the group termed miscellaneous, i.e. all those not included in the definitely named classes, have expectations between the two. The expectations of life for the clergy in the different epochs are usually in excess of those shown by all eminent men taken together at the

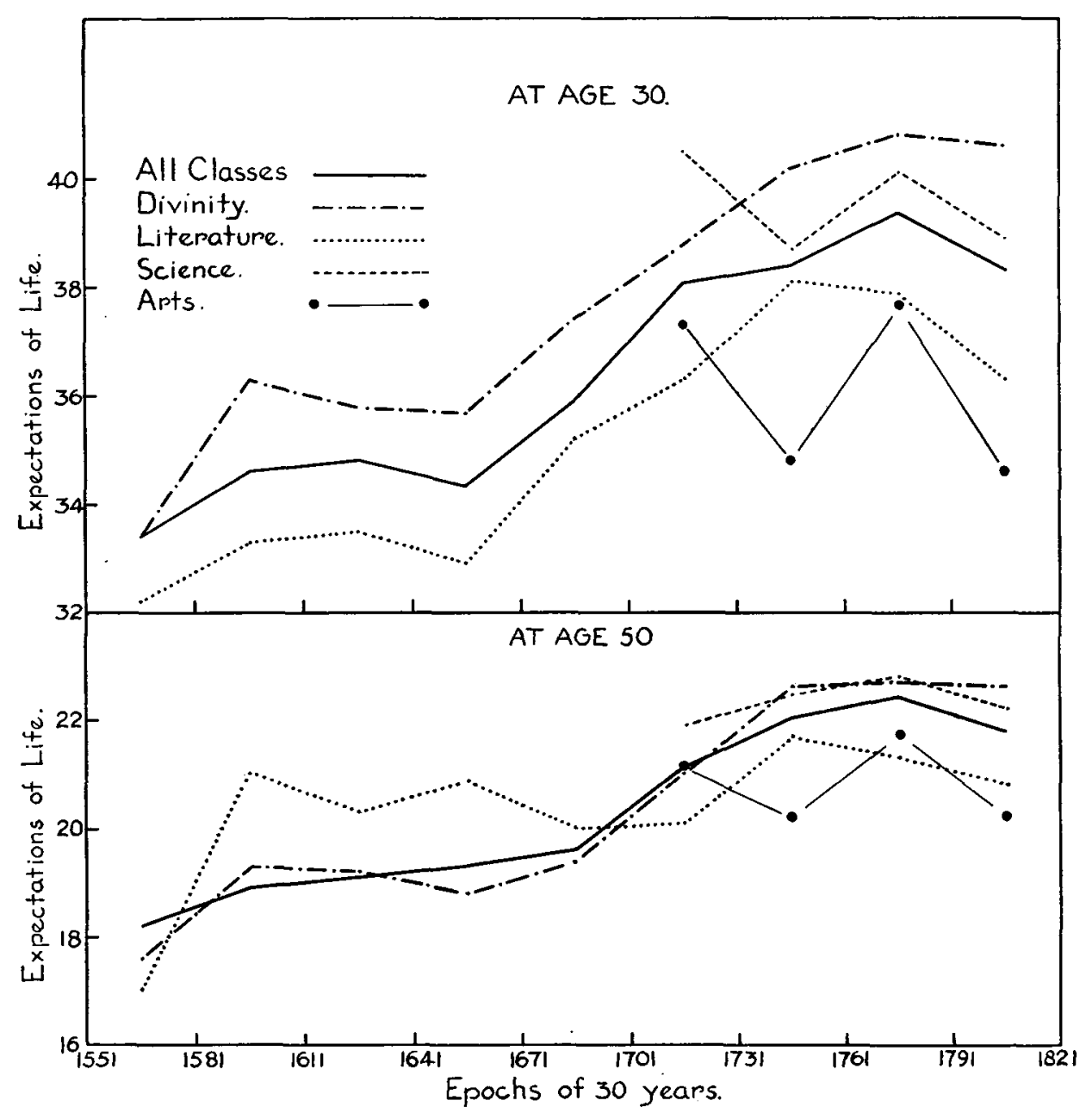

Graph II. Showing, for several classes of eminent men, the expectations of life at ages 30 and 50 in successive 30 years' epochs from 1551 to 1820 .

corresponding ages whereas the expectations of literary men fall short of these. The differences between the expectations in clergymen and literary men at age 30 are so relatively small compared with their probable errors that they cannot be considered sensible in the three earlier epochs. In the last two periods, however, the differences in expectation at this age are apparently significant. 
For the periods 1731-60 and 1791-1810, it is possible to compare the expectations of life of men who adopted science as a profession and those who come under the designation arts, with the expectations for the clergy, for literary men and for eminent men in general. The expectations for men who attained eminence in science agree fairly closely with the expectations of eminent men in the aggregate, but the expectations for those who attained eminence in arts are distinctly lower than those for the other groups tabulated, the expectation at age 30 years in the two periods cited being about three and a half years less than that for eminent men as a whole. When the values of the expectations at age 50 are compared, it is found that the differences in the values for clergymen and literary men are relatively small and insignificant statistically except in the most recent period investigated, namely, 17911810. The lower expectations in literature than in divinity at the early ages may be due to the fact that attainment of success in literature is more easy in early life and that consequently the number of deaths recorded in this profession at the earlier ages is relatively great. Amongst those in the category arts, the expectations at 50 are still definitely lower than those for eminent men as a whole and for the majority of the other classes. It is difficult to suggest a reason for the relatively low vitality shown by men of eminence in this sphere of life.

Another aspect of the subject to which a brief reference may be made is the relationship between conjugal condition and longevity. It has been shown in life tables constructed from recent data, that the expectation of life for married men is definitely greater than that for unmarried men. It seemed to be of interest to determine if this feature was of modern development or if it was already established in pre-registration times. The data available for the peerage and baronetage for this period made it possible to calculate tables to show how expectation of life varied with conjugal condition in the highest social class. From the data for those born between 1761 and 1820 who married and remained unmarried, respectively, expectations of life at five-yearly intervals from age 25 upwards were calculated. These are shown in Table V in association with the expectations of life calculated by Dunlop (1924) for corresponding marital groups in Scottish data for 1921.

It will be seen from the table that the expectations of life of the married in the peerage are at all ages in fairly close agreement with those exhibited by the Scottish males at the corresponding ages living in a period approximately 100 years later. Amongst the unmarried in the Scottish data, the expectations of life at ages 25 and 30 are decidedly less than for the married, the difference at age 25 being 5 years and at $30,4 \cdot 6$ years. For the unmarried in the peerage data, the expectations at 25 and 30 are still less favourable than those shown for the Scottish data. The expectations from age 40 upwards are, however, not very dissimilar in the two groups of unmarried. The relatively low expectations of life of the unmarried as compared with the married in the Scottish and similar data are usually attributed in large measure to the 
circumstance that some considerable selection of the fittest for marriage takes place, although other factors may also be operative. Many who remain unmarried under 30 , do so because of impaired health, and the proportion of those under 35 with relatively poor health who remain unmarried is higher than amongst the married. The sensibly lower expectation of life of the unmarried in the peerage than in the Scottish data for unmarried men of the whole community at the ages under 30 , is probably to be explained in some measure by the fact that impaired health plays a relatively larger part in preventing marriage in the peerage than amongst people in general and that men of the

Table V. Showing the expectations of life at different ages in married and unmarried males in data derived from Burke's Peerage for those born in the period 1761-1820, in comparison with the expectation of those in corresponding marital conditions in mortality data for Scotland in 1921.

\begin{tabular}{|c|c|c|c|c|}
\hline \multirow[b]{2}{*}{ Age } & \multicolumn{2}{|c|}{ Married } & \multicolumn{2}{|c|}{ Unmarried } \\
\hline & $\begin{array}{c}\text { Burke's Peerage } \\
1761-1820 \\
(6656)^{*}\end{array}$ & $\begin{array}{c}\text { Scotland } \\
1921\end{array}$ & $\begin{array}{c}\text { Burke's Peerage } \\
1761-1820 \\
(769)^{*}\end{array}$ & $\begin{array}{c}\text { Scotland } \\
1921\end{array}$ \\
\hline 25 & $41 \cdot 94$ & $41 \cdot 24$ & $30 \cdot 82$ & $36 \cdot 37$ \\
\hline 30 & 37.53 & 36.95 & $29 \cdot 14$ & $32 \cdot 32$ \\
\hline 35 & $33 \cdot 40$ & $32 \cdot 75$ & 27.25 & $28 \cdot 47$ \\
\hline 40 & $29 \cdot 35$ & $28 \cdot 58$ & $25 \cdot 33$ & $24 \cdot 80$ \\
\hline 45 & 25.63 & $24 \cdot 51$ & $22 \cdot 55$ & $21 \cdot 24$ \\
\hline 50 & $21 \cdot 92$ & $20 \cdot 59$ & $19 \cdot 40$ & $17 \cdot 92$ \\
\hline 55 & 18.29 & $16 \cdot 89$ & $16 \cdot 47$ & $14 \cdot 80$ \\
\hline 60 & $14 \cdot 94$ & $13 \cdot 53$ & $13 \cdot 24$ & $11 \cdot 96$ \\
\hline 65 & $11 \cdot 77$ & 10.57 & 10.54 & $9 \cdot 50$ \\
\hline 70 & 8.93 & $8 \cdot 00$ & $8 \cdot 13$ & $7 \cdot 15$ \\
\hline 75 & $6 \cdot 74$ & 5.89 & $6 \cdot 78$ & $5 \cdot 38$ \\
\hline 80 & $4 \cdot 91$ & $4 \cdot 31$ & $4 \cdot 80$ & $4 \cdot 00$ \\
\hline
\end{tabular}

peerage do not require to any appreciable extent to postpone or avoid marriage for economic reasons which are such important factors in causing the deferment or the avoidance of marriage by men in the general community.

The value which the statistics have in illustrating the changes which have taken place in the healthiness of England from the sixteenth, to the beginning of the nineteenth century, now falls to be appraised. Apart from environmental conditions, little is known at present regarding the circumstances which cause variation in vitality as indicated by average length of life. Suitable data are not available to elicit the influence on longevity of other factors which may probably be mainly biological. It is doubtful to what extent the change in average duration of life in the specially favoured classes, the peerage and baronetage and men of eminence, may be accepted as a criterion of what has taken place in the community as a whole; the presumption is that increased duration of life in these, even though they are subject to more favourable environmental conditions, would be accompanied by a more or less parallel increase in longevity, but an increase at a lower level, amongst the general community. In the present data, taking the expectation of life at 30 years of age as a criterion of healthiness, its variation has been traced from 1551 
throughout nearly three centuries. From the expectations of life in eminent men, it has been seen that the expectation increases in successive periods from the middle of the sixteenth century till the end of the eighteenth century. The increases in successive epochs are seldom large. Sometimes, as in the seventeenth century, slight decreases occur, but the value of these in most cases is so small as to be within the range of statistical error due to random sampling. There is, however, one considerable change in the expectation between males born in the second half of the seventeenth century and those born in the early part of the eighteenth. The gain in expectation of life in this interval amounts almost to four years. After this the increase in mean afterlifetime is continuous till a maximum is reached among those born towards the end of the eighteenth century. A slight but sensible decline in the expectation is shown for those born subsequently, but as this decline is not very marked and the investigation ends at 1810 , it is impossible to be certain that the decline is not merely a temporary phase as would be suggested from the data for the peerage.

From other sources, there is some information about the general deathrate in England in the eighteenth century. Brownlee (1916) has brought forward evidence which suggests that the general death-rate at all ages in England increased between the years 1700 and 1740, and that from the latter date it has steadily declined. The exact mortality-rates are not certain but can be put at about 30 per thousand in 1700 , and 35 per thousand in 1740 . It would thus seem that those born in the last 30 years of the seventeenth century were born into a country with a rising death-rate, whereas the majority of those born at the beginning of the eighteenth century would, by the time they attained the age of 30 , be living in a country with a falling death-rate. The rise in the expectation of life that has been shown to occur in these periods is thus in agreement with what has been found by Brownlee in the later epoch. It should be noted as probably more than a coincidence, that the 20 years' period $1770-90$, in which a maximum mean after-lifetime appears to occur in our data for eminent men, was an age during which more persons of the first rank were born than in any other 20 years in the last three centuries. Brownlee (1908) considers that epochs of genius are epochs of special vitality and this investigation seems to indicate that vitality was higher during the period in question than it was in that immediately following.

\section{ConCLUSIONS.}

The results of the foregoing analysis seem to indicate quite definitely that a considerable improvement in the vitality of both men of eminence and of the best social classes in England took place in the three hundred years from the sixteenth to the beginning of the nineteenth century, an improvement more or less equivalent to what would be observed if the conditions of health that obtained in England as a whole in 1881-1900 were brought to the level of those that prevail in the country districts at the present day. Though it 
must be freely acknowledged that the change in the most favoured classes can only be regarded as an approximate index of what occurred amongst people as a whole, it seems reasonable to infer that an increase in average duration of life, at least equivalent to, though on a lower level than that seen in the former, also took place in the general community.

\section{REFERENCES.}

Brownlee, J. (vr. and vir. 1916). The History of the Birth and Death-rates in England and Wales taken as a whole, from 1570 to the present time. Public Health.

(Iv. 1908). Germinal Vitality. Proc. Roy. Phil. Soc. Glasgow,

DAY, A. and BaILEY, A. H. (1861). On the Rate of Mortality prevailing amongst the Families of the Peerage during the Nineteenth Century. J. Inst. Actuaries, Ix. 305.

Duncop, J. C. (1924). Scottish Life Tables, 1921. Trans. Faculty of Actuaries, x. Pt I, No. 92.

Edmonds, T. R. (1839). On the Duration of Life in the English Peerage. Lancet, I.

GuY, W. A. (1845). On the Duration of Life amongst the Families of the Peerage and Baronetage of the United Kingdom. J. Roy. Stat. Soc. virr. 69.

LeckY, W. E. H. (1887). History of England in the XVIII Century, v. 26. London: Longmans, Green and Co.

(MS. received for publication 20. v. 1926.-Ed.) 